\title{
Geographic contingency, not species sorting, dominates macroevolutionary dynamics in an extinct clade of neogastropods (Volutospina; Volutidae)
}

\author{
Dana S. Friend* (D), Brendan M. Anderson (1D, and Warren D. Allmon
}

\begin{abstract}
Rates of speciation and extinction are often linked to many ecological factors, traits (emergent and nonemergent) such as environmental tolerance, body size, feeding type, and geographic range. Marine gastropods in particular have been used to examine the role of larval dispersal in speciation. However, relatively few studies have been conducted placing larval modes in species-level phylogenetic context. Those that have, have not incorporated fossil data, while landmark macroevolutionary studies on fossil clades have not considered both phylogenetic context and net speciation (speciation-extinction) rates. This study utilizes Eocene volutid Volutospina species from the U.S. Gulf Coastal Plain and the Hampshire Basin, U.K., to explore the relationships among larval mode, geographic range, and duration. Based on the phylogeny of these Volutospina, we calculated speciation and extinction rates in order to compare the macroevolutionary effects of larval mode. Species with planktotrophic larvae had a median duration of 9.7 Myr, which compared significantly to $4.7 \mathrm{Myr}$ for those with non-planktotrophic larvae. Larval mode did not significantly factor into geographic-range size, but U.S. and U.K. species do differ, indicating a locality-specific component to maximum geographic-range size. Non-planktotrophs (NPTs)were absent among the Volutospina species during the Paleocene-early Eocene. The relative proportions of NPTs increased in the early middle Eocene, and the late Eocene was characterized by disappearance of planktotrophs (PTs). The pattern of observed lineage diversity shows an increasing preponderance of NPTs; however, this is clearly driven by a dramatic extinction of PTs, rather than higher NPT speciation rates during the late Eocene. This study adds nuance to paleontology's understanding of the macroevolutionary consequences of larval mode.
\end{abstract}

Dana S. Friend and Warren D. Allmon. Paleontological Research Institution, 1259 Trumansburg Road, Ithaca, New York 14850 U.S.A. E-mail:dsf88@cornell.edu,wda1@cornell.edu

Brendan M. Anderson. Department of Geosciences, Baylor University, 101 Bagby Avenue, Waco, Texas 76706 U.S.A. E-mail: Brendan_Anderson@baylor.edu

Accepted: 6 December 2020

*Corresponding author.

\section{Introduction}

Many ecological factors have been suggested as influencing rates of speciation and extinction, including feeding type (Levinton 1974), population size (Boucot 1975), range of environmental tolerance (Jackson 1974), and dispersal ability (Lester et al. 2007). Marine gastropods in particular have been the subject of much study of the role of dispersal in speciation (Hansen 1978; Jablonski 1987; Jablonski and Valentine 1990; McKinney 1997; Crampton et al. 2010). However, relatively few studies have been conducted placing larval modes in species-level phylogenetic context (Collin 2004; Krug et al. 2015; Sang et al. 2019). Those that have, have not incorporated fossil data, while landmark macroevolutionary studies on fossil clades (Jablonski and Lutz 1983; Jablonski 1986; Hansen 1997) have not considered both phylogenetic context and net speciation (speciation-extinction) rates (Krug et al. 2015). Traits that lead to increasing rates of speciation might also lead to a proportionally greater increase in rates of extinction, resulting in lower net diversification of the clade possessing said trait (Goldberg et al. 2010).

Gastropods are among the many marine invertebrates that undergo a two-stage life cycle. The adult gastropod body plan typically results in restricted mobility relative to the

(C) The Author(s), 2021. Published by Cambridge University Press on behalf of The Paleontological Society. This is an Open Access article, distributed under the terms of the Creative Commons Attribution licence (http://creativecommons.org/ licenses/by/4.0/), which permits unrestricted re-use, distribution, and reproduction in any medium, provided the original work is properly cited. 
dispersal that occurs while in the larval form. Two larval types (or developmental modes) are generally recognized in the literature: planktotrophic and non-planktotrophic (Thorson 1950; Jablonski and Lutz 1983). Planktotrophs (PTs) feed on the plankton, meaning their dispersal potential is not nutrient limited (Thorson 1950), and the adults produce relatively larger numbers of eggs. Non-planktotrophs (NPTs) have a higher per-offspring investment, potentially increasing survival, but produce fewer eggs (Jablonski and Lutz 1980). NPTs include species with both lecithotrophic (planktonic, but yolk-feeding) and direct-developing larvae. Because non-planktotrophic larvae lack the structures that facilitate feeding within the plankton, they are expected to have more restricted dispersal and consequently both lower population interconnectivity (potentially increasing speciation rates) and smaller geographic ranges (potentially increasing extinction risk; Jablonski and Lutz 1980). The exact nature of the relationship between geographic range and speciation is paradoxical (Jablonski 2017), as greater dispersal ability may lead to either increased chances of the formation of peripheral isolates or higher interpopulation connectivity, depressing speciation (Boucot 1975; Stanley 1986; Allmon and Martin 2014).

The consequences of larval ecology in macroevolutionary processes have long been discussed in the paleobiological literature. Jackson (1974) and Scheltema (1977, 1978, 1979) developed a model to think about the effect of larval dispersal ability (i.e., larval type) on speciation and extinction rates. In this model, species with planktotrophic larvae (and thus the potential to disperse over a large geographic area) can easily maintain gene flow between populations, because larvae from outside populations constantly "replenish" (Zelnik et al. 2015) populations that are reduced by local disturbances (which are not likely to completely extinguish a widespread species from its whole geographic range). These conditions theoretically result in species with long durations, and lineages display low extinction rates. Species with non-planktotrophic larvae are likely to have more restricted geographic ranges, and extinction is more likely to occur due to local disturbances and randomly fluctuating populations. Consequently, NPTs are generally predicted to have a geologically short duration, and lineages are predicted to have higher extinction rates (Jablonski and Lutz 1983). Depending on the environmental or ecological mechanisms driving extinction, however, either planktotrophy or non-planktotrophy may be selectively advantageous for reasons unrelated to dispersal potential (Shuto 1974; Jablonski and Lutz 1980); for example, nonplanktotrophy may be favored when regional productivity declines (Sang et al. 2019).

Dispersal ability also affects the rate of speciation. Wide dispersal of larvae effectively mixes genes from disjunct populations, suppressing genetic divergence required for speciation. This model hypothesizes, then, that planktotrophic lineages have relatively low speciation rates. In contrast, larvae with restricted dispersal ability form local populations that remain isolated after the initial colonization, meaning NPT lineages likely have higher speciation rates. The end result of this model is that planktotrophic species have relatively longer durations, lower extinction rates, and low speciation rates; while species with non-planktotrophic larvae have relatively shorter durations, higher extinction rates and higher speciation rates. Alternatively, planktotrophic lineages may have more opportunities to form peripheral isolates, leading to high speciation rates as well.

A primitive planktotrophic larval mode characterizes many gastropod clades, as determined by phylogenetic methods, for example, Turritellidae (Lieberman et al. 1993; Sang et al. 2019), Kermia and Pseudodaphnella (Fedosov and Puillandre 2012), Conus (Duda and Palumbi 1999), and neogastropods (Hansen 1982). However, while planktotrophic species usually give rise to non-planktotrophic species, the reverse seems to be a rare exception (Reid 1989). Of the groups mentioned, direct development has independently arisen at least two times, and there were no reversals back to planktotrophy. The lack of reversals can be attributed to the inability to redevelop the specialized feeding and swimming features that characterize planktotrophic larvae once they have been lost (e.g., Strathmann 1974, 1978). High rates of irreversible character change can result in the accumulation of distantly related NPTs in the fossil record, similar to state- 

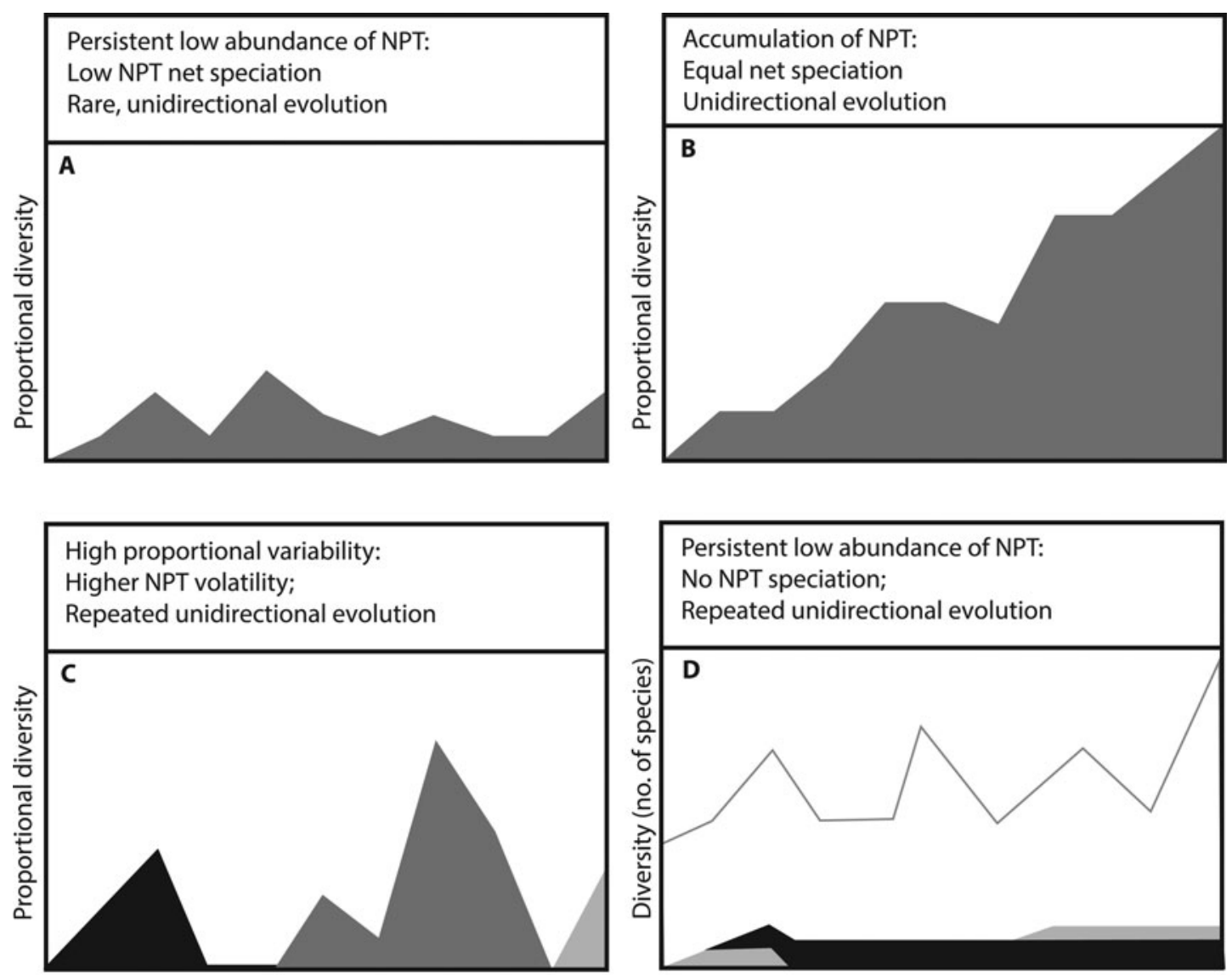

Time (10 arbitrary timesteps)

FIGURE 1. Proposed effects of non-planktotrophy on the proportion of planktotrophic (PT) taxa (white) to nonplanktotrophic (NPT) taxa (filled) based on speciation and extinction rates in four theoretical models of macroevolution. A, Rare origins of new non-planktotrophic lineages from planktotrophic taxa coupled with low speciation rates lead to persistence at low relative diversity. B, Non-planktotrophic lineages of equal or higher net speciation than planktotrophic lineages accumulate passively due to the one-way nature of the transitions. C, Non-planktotrophic lineages with higher rates of both speciation and extinction due to their low population sizes and low connectivity would result in strong fluctuations of relative diversity, with frequent extinction of non-planktotrophic lineages. D, For non-planktotrophic lineages with extremely low speciation rates, the total diversity is dictated by the frequency of new non-planktotrophic lineages from planktotrophic taxa relative to extinction rate.

dependent diversification (which is one aspect of species sorting) (Duda and Palumbi 1999).

Exceptions are seen in Lacuninae (Littorinidae) (Reid 1989) and Crepipatella (Calyptraeidae) (Collin et al. 2007), for which reversals from nonplanktotrophy to planktotrophy are inferred. In such cases, non-planktotrophic larvae retain the specialized feeding and swimming structures, making the transition from non-planktotrophy back to planktotrophy possible (Collin 2004; Collin et al. 2007; Collin and Miglietta 2008).
Little empirical evidence has been produced regarding the macroevolutionary effects of larval mode in phylogenetic context (Krug et al. 2015). There are various reasonable macroevolutionary scenarios that may be governed by larval mode, if one considers transitions unidirectional from planktotrophy to non-planktotrophy:

1. NPTs may have rare origins from PTs and lower speciation rates, leading to persistence at low relative diversity (Fig. 1A). 
2. NPTs may have equal or higher net speciation (speciation-extinction) rates and accumulate passively due to the one-way nature of the transitions (Fig. 1B).

3. NPTs may have higher speciation and extinction rates due to their low population sizes and low connectivity. This high volatility (Gilinsky 1994; J. C. Lamsdell, personal communication) would result in strong fluctuations of relative diversity, but frequent extinction of non-planktotrophic lineages (Fig. 1C).

4. NPTs may have extremely low speciation rates. Under these conditions, the total diversity of NPTs is dictated by the frequency of transitions relative to extinction (Fig. 1D). It is possible to envision a scenario (however unlikely) in which NPTs never speciate but there is a higher than $50 \%$ production of NPTs during planktotrophic speciation events coinciding with larval mode transitions. This would eventually drive the clade to extinction through decreasing speciation rates without necessarily requiring increased extinction rates.

Larval type can often be confidently inferred from fossil gastropod shells, because the size and shape of the protoconch (larval shell) (Vendetti 2007; Sang et al. 2019) differ between the two modes. A large protoconch with few whorls (paucispiral) indicates a non-planktotrophic larval stage after hatching from a large yolked egg, whereas small, multispiral protoconchs generally indicate a longer planktonic period (PT).

Investigations into potential connections between larval type and evolutionary patterns in several neogastropod families (e.g., Hansen 1978, 1982) found that (consistent with the model outlined in Jackson [1974] and Scheltema [1977]) species with non-planktotrophic larvae had narrower geographic ranges than species with planktotrophic larvae. Crampton et al. (2010) modeled the relationships between geographic range, species duration, size, and other traits in mollusks and found positive relationships between body size and geographic range as well as geographic range and species duration. Gastropod species duration displayed two-way associations between life mode (e.g., infaunal, epifaunal), and feeding type (e.g., deposit-feeder, grazer, carnivore). Planktotrophic larval type was associated with wide geographic range only via species duration (through a three-way interaction). Other authors found that geographic range and duration had a reciprocal relationship in marine invertebrates and microfossils. Foote et al. (2008) concluded that duration determines range as much as range determines duration.

While the studies cited have supplied an abundance of data on the associations between larval ecology and species-level traits (i.e., traits emergent at the species level; Jablonski 2000, 2017; Congreve et al. 2018) of geographic range and population interconnectivity, they did not explicitly test the macroevolutionary outcomes (in terms of speciation and extinction). In other words, they did not test for species selection (Stanley 1975; Krug et al. 2015). While Krug et al. (2015) examined larval mode selection in a phylogenetic context, their results are not comparable to other tests of species sorting and selection, because no sea slug fossil lineages were included when calculating net speciation. Other authors have noted the problems in inferring speciation and extinction rates using phylogenies constructed with only extant species (Quental and Marshall 2009; Liow et al. 2010; Rabosky 2010; Marshall 2017).

Early investigators focused on differential survival of species based on organismal traits present in all members of a given species (Stanley 1975, 1979; Arnold and Fristrup 1982; Coyne and Orr 2004; Okasha 2006), more precisely termed "species sorting" (Vrba and Gould 1986; Lieberman and Vrba 1995). But in its strict sense, species selection refers to the emergent fitness (differential origination and extinction of species) within clades due to species-level emergent traits, while the observation of differential outcomes among species as a result of unexpected (emergent) higherlevel consequences of traits possessed by all individuals of a species is more properly termed "species sorting" (Vrba and Gould 1986; Jablonski 2000).

Hansen's (1978) research on Paleogene Volutidae (Neogastropoda) found that the first appearance of non-planktotrophy resulted in 
more appearances of non-planktotrophic species, but in the absence of phylogenetic context, the frequency of larval mode transitions remains unknown, as do which lineages (PTs or NPTs) have higher speciation, extinction, or net-speciation rates. In his attempt to link larval mode with speciation, Hansen assumed that larval mode transitions were unidirectional and that the accumulation of NPTs is exponential (scenario shown in Fig. 1B). He concluded that increased speciation rates resulting from restricted dispersal ability (via larval mode transition) could have resulted in the strictly non-planktotrophic family of extant volutids (Darragh and Ponder 1998; Penchaszadeh et al. 1999). Yet the prevalence of planktotrophic species in families other than Volutidae argues against the possibility that there is a universal advantage, independent of other traits and environmental circumstances, to having non-planktotrophic larvae.

Here we reexamine Hansen's conclusions on the effects of dispersal ability (via larval type) on speciation and evaluate several scenarios that could be responsible for the proportional increase in NPTs to PTs over geologic time in Volutidae. For larval mode switches to have produced the dominance of non-planktotrophy, several plausible scenarios are considered: (1) many unidirectional switches from planktotrophy to non-planktotrophy occurred in multiple different subclades; (2) only a few switches to the non-planktotrophic mode, along with the differential diversification of lineages with non-planktotrophic larvae; and finally (3), species selection could be implicated if the difference in net rate of speciation favoring NPTs is found to offset any differences in rate of extinction. These are not mutually exclusive scenarios, however, but rather independent hypotheses to test.

To minimize the effect of factors other than dispersal ability, a single genus within Volutidae, Volutospina, was chosen for detailed analysis. The taxonomy and systematics of this clade were recently analyzed (Friend 2021), and a phylogeny produced therein provides the phylogenetic context for this study (Fig. 2). The Paleocene-Eocene outcrops of the U.S. Gulf Coastal Plain (GCP) and the AngloParisian Basin (APB) provide an excellent framework for testing the effect of dispersal potential (larval mode). The stratigraphy of both regions has been extensively studied, and fossil mollusks are generally well preserved.

\section{Methods}

For all but one ( $V$. arangia) species, multiple specimens with complete protoconchs were studied under a microscope to determine larval mode. Larval inferences for rare taxa and worn, fragmented, or poorly preserved species were based on a single specimen, but larval type is largely thought to be species specific (Robertson 1974). None of the taxa with multiple protoconch-bearing specimens displayed intraspecific variation in larval type. Following the method outlined by Shuto (1974), we used the ratio between maximum diameter (D) and number of volutions of the protoconch $(\mathrm{Vol})$ to infer each species' larval type (D/Vol). Planktotrophic larvae have $\mathrm{D} / \mathrm{Vol}$ ratios of less than 0.3; at least 3 volutions; and a thin, acute apex. Non-planktotrophic larvae have D/Vol ratios 0.3 and above; fewer than 2.25 volutions; and a blunt, low apex. But when $\mathrm{D} / \mathrm{Vol}$ ratio is between 0.3 and 1.0 and the protoconch more than 3 volutions, both planktotrophy and non-planktotrophy are possible, and qualitative characters like sculpture and shape help infer larval mode (Shuto 1974; Vendetti 2007).

Following the methods of Hansen (1980), maps of the GCP and the APB were divided into linear geographic units, each $75 \mathrm{~km}$ wide. Locality data for each species were collected from both published literature and museum specimens. Paleobiogeographic ranges of Volutospina species were calculated by mapping occurrences and counting the number of geographic units (Hansen 1980) between its most distant localities. To avoid giving species an anomalously wide distribution, geographic units were counted for only the stratigraphic unit during which the species occupied the most zones.

Species durations (stratigraphic ranges) were calculated by summing the durations of nanoplankton (NP) zones of the geologic formations in which each was present. NP ages were based on Papazzoni et al. 2017 (Table 1). Mann- 


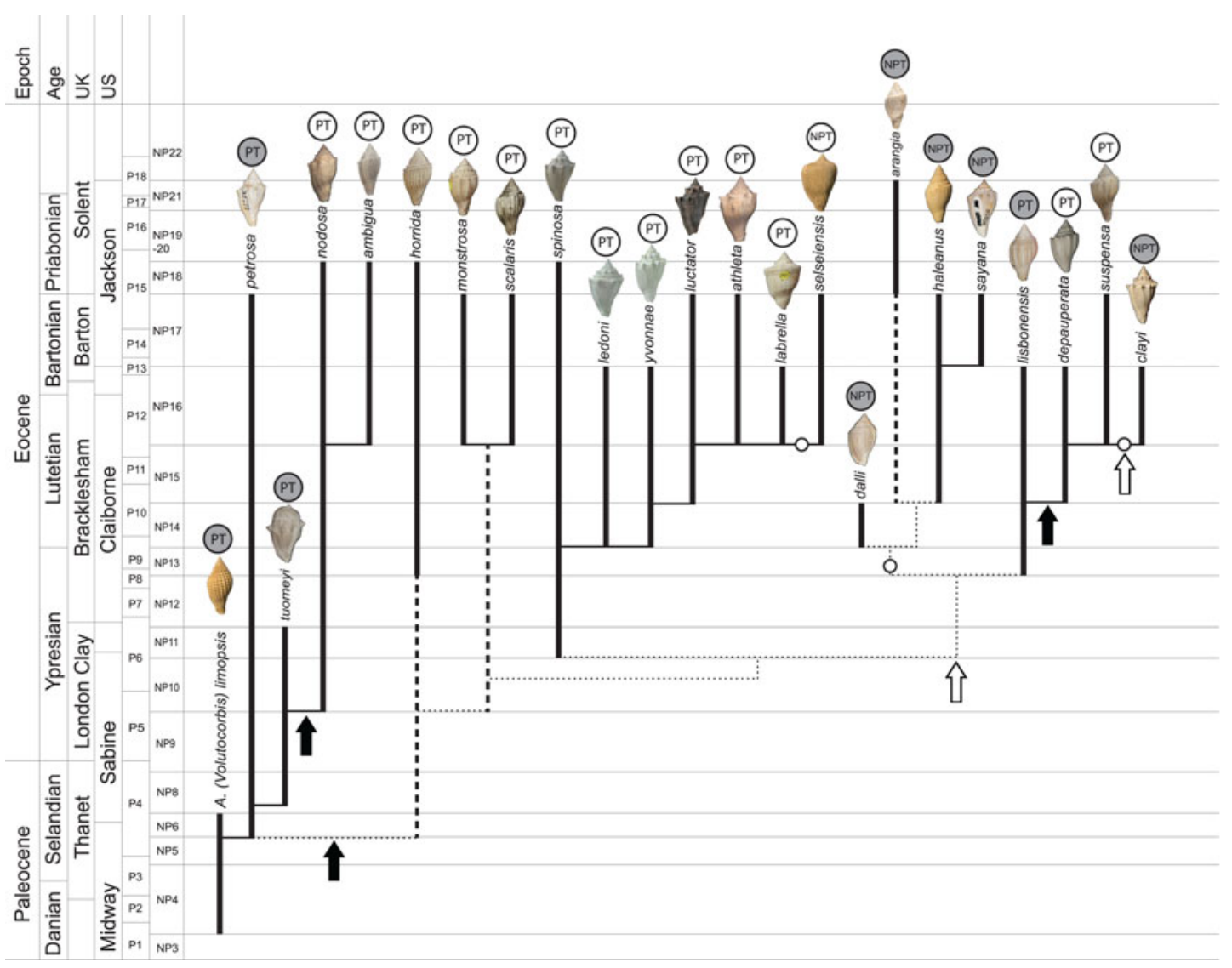

FIGURE 2. Phylogeny of Paleocene-Eocene Volutospina. PT, planktotrophic; NPT, non-planktotrophic; gray circle labels, U.S. species; white circle labels, U.K. species; white circles on phylogeny, larval mode change from planktotrophic to nonplanktotrophic. Black arrows, west to east Atlantic larval dispersal; white arrows, east to west Atlantic larval dispersal.

TABLE 1. Nanoplankton (NP) boundary ages and duration. Number of planktotrophs (PTs) and non-planktotrophs (NPTs) present in each zone.

\begin{tabular}{lccrc}
\hline \hline & $\begin{array}{c}\text { Age at upper and } \\
\text { lower boundaries } \\
\text { NP zone }\end{array}$ & $\begin{array}{c}\text { Duration } \\
\text { (Myr) }\end{array}$ & $\begin{array}{c}\text { No. } \\
\text { of } \\
\text { PTs }\end{array}$ & $\begin{array}{c}\text { No. of } \\
\text { NPTs }\end{array}$ \\
\hline NP5 & $59.5-61.4$ & 1.9 & 1 & 0 \\
NP6 & $59.0-59.5$ & 0.5 & 3 & 0 \\
NP8 & $57.2-58.4$ & 1.8 & 3 & 0 \\
NP9 & $55.8-57.2$ & 1.4 & 3 & 0 \\
NP10 & $54.2-55.8$ & 1.6 & 6 & 0 \\
NP11 & $53.7-54.2$ & 0.5 & 7 & 0 \\
NP12 & $50.6-53.7$ & 3.1 & 7 & 0 \\
NP13 & $49.2-50.6$ & 1.4 & 6 & 1 \\
NP14 & $46.4-49.2$ & 2.8 & 8 & 2 \\
NP15 & $42.8-46.4$ & 3.6 & 10 & 2 \\
NP16 & $40.6-42.8$ & 2.2 & 15 & 4 \\
NP17 & $37.4-40.6$ & 3.2 & 10 & 4 \\
NP18 & $36.8-37.4$ & 0.6 & 4 & 1 \\
NP19-20 & $34.4-36.8$ & 2.4 & 0 & 1 \\
NP21 & $34.4-33.0$ & 1.4 & 0 & 1 \\
NP22 & $33.0-32.5$ & 0.5 & 0 & 0 \\
\hline
\end{tabular}

Whitney $U$-tests, calculated in PAST v. 3.24 (Hammer et al. 2001) were used to assess the relationship between larval type and emergent traits (geographic range and species duration).

The potential interactive effect of geographic range and duration was explored using a multiple logistic regression analysis in the Quest Graph Logistic Regression Calculator (ATT Bioquest, Inc., 2019). Although this test is not without criticism, particularly because it assumes normality and treats dependent variables as independent, it does give some indication as to which variable is the strongest predictor of larval mode.

Larval mode was mapped onto Friend's (2021) phylogeny of Paleocene and Eocene Volutospina to assess the origin of NPTs and to determine the number of lineage originations and 
extinctions in each NP zone for both PTs and NPTs. Per-lineage speciation and extinction rates were calculated for each by observing the number of new species or the number of lineages ending at the base of each NP zone. The rates of per-lineage speciation and extinction were then calculated using the duration (in millions of years) of the NP zone immediately before the boundary where measurements were taken. Comparisons between NPTs and PTs across the entire history of the clade (as opposed to within an NP zone) included all time periods for which lineages existed representing the larval mode under consideration. An unequal variance $t$-test comparing perlineage, per-million years net-speciation rates was also performed in PAST v. 3.24 (Hammer et al. 2001).

\section{Results}

The larval modes of Eocene Volutospina are summarized in Table 2 (protoconchs were located for all species except $V$. arangia). Of the species included in this analysis, six

TABLE 2. Larval mode (PT, planktotroph; NPT, non-planktotroph), species duration, provenance (GCP, U.S. Gulf Coastal Plain; APB, Anglo-Parisian Basin), and maximum geographic-range size (in units of $75 \mathrm{~km}$, as in Hansen [1980]) of Volutospina species.

\begin{tabular}{lllcc}
\hline \hline Species & Region & $\begin{array}{l}\text { Larval } \\
\text { mode }\end{array}$ & $\begin{array}{c}\text { Duration } \\
\text { (Myr) }\end{array}$ & $\begin{array}{c}\text { Geographic } \\
\text { range }\end{array}$ \\
\hline ambigua & APB & PT & 6.0 & 7 \\
arangia & GCP & $?$ & 4.4 & 1 \\
athleta & APB & PT & 9.0 & 6 \\
clayi & GCP & NPT & 2.2 & 1 \\
dalli & GCP & NPT & 2.8 & 4 \\
depauperata & APB. & PT & 5.8 & 1 \\
haleana & GCP & NPT & 9.0 & 21 \\
horrida & APB & PT & 13.8 & 1 \\
labrella & APB & NPT & 5.8 & 2 \\
ledoni & APB & PT & 8.6 & 2 \\
lisbonensis & GCP & PT & 10.0 & 16 \\
luctator & APB & PT & 9.0 & 1 \\
monstrosa & APB & PT & 5.4 & 2 \\
nodosa & APB & PT & 19.0 & 2 \\
petrosa & GCP & PT & 22.1 & 40 \\
sayana & GCP & NPT & 3.2 & 2 \\
scalaris & APB & PT & 5.4 & 1 \\
selseiensis & APB & NPT & 5.4 & 1 \\
spinosa & APB & PT & 17.4 & 8 \\
suspensa & APB & PT & 5.4 & 1 \\
tuomeyi & GCP & PT & 5.3 & 22 \\
yvonnae & APB & PT & 8.6 & 1 \\
limopsis & GCP & PT & 4.0 & 17 \\
\hline & & & &
\end{tabular}

TABLE 3. Results of Mann-Whitney $U$-tests. ${ }^{* *}$ significant p-value. PT, planktotrophs; NPT, non-planktotrophs; GCP, U.S. Gulf Coastal Plain; APB, Anglo-Parisian Basin.

\begin{tabular}{llccc}
\hline \hline Trait & Comparison & $U$-value & $z$-score & $p$-value \\
\hline $\begin{array}{l}\text { Geographic } \\
\text { range }\end{array}$ & NPT and PT & 42 & 0.935 & 0.350 \\
$\begin{array}{l}\text { Geographic } \\
\quad \text { range }\end{array}$ & GCP and & 32 & 1.991 & $0.046^{* *}$ \\
$\begin{array}{l}\text { Duration } \\
\text { Speciation rate }\end{array}$ & NPT and PT & 20 & 2.381 & $0.017^{* *}$ \\
Extinction rate & NPT and PT & 38.5 & 0.728 & 0.447 \\
\hline
\end{tabular}

definitively indicate non-planktotrophic larvae. These six include four GCP species and two APB species. The test results that follow treated $V$. arangia as an NPT (a reasonable inference as a member of NPT-only clade), but statistical analyses found that treating it as non-planktotrophic did not ultimately have an effect on final results.

Patterns of species distribution reveal the differences in geographic ranges between species with presumably similar dispersal abilities. For example, some planktotrophic species exhibited restricted geographic ranges (e.g., $V$. depauperata, $V$. horrida, and $V$. luctator). Considering all taxa together, the difference of geographic range between PTs and NPTs is insignificant, as determined by Mann-Whitney $U$-tests $(p=0.350)$ (Table 3$)$. The analysis here indicates that these volutids exhibited little difference in geographic range between different larval modes. Results of a Mann-Whitney $U$-test between GCP and APB species, however, shows GCP species had significantly larger geographic ranges $(p=0.046)$ and indicates a locality-specific component to maximum geographic-range size (Table 3).

Species with non-planktotrophic larvae had a median duration of 4.7 Myr but 9.7 Myr for those with planktotrophic larvae. A Mann-Whitney $U$-test (Table 3) indicates that this difference between species durations of PTs and NPTs is significant ( $p=0.017)$.

The interactive effect of both duration and geographic range, as measured by multiple logistic regression, revealed that duration had a closer correlation with larval modes than geographic-range size (Table 4). In other words, duration was a better predictor for larval mode than geographic-range size. 
TABLE 4. Results of the multiple logistic regression analysis.

\begin{tabular}{lcccr}
\hline \hline Variable & Coefficient & $\begin{array}{c}\text { Standard } \\
\text { error }\end{array}$ & $p$-value & $z$-value \\
\hline Constant & 3.6892 & 2.0096 & 0.0664 & 1.8358 \\
$\begin{array}{l}\text { Duration } \\
\begin{array}{l}\text { Geographic } \\
\text { range }\end{array}\end{array}$ & -0.6033 & 0.3267 & 0.0648 & -1.8463 \\
\hline
\end{tabular}

The number of species in each NP zone grew modestly from NP 4 to 12, peaked in NP 16 (Table 1), and dropped quickly after NP 18. The results of this analysis indicate that nonplanktotrophy was absent among the Volutospina species during the Paleocene and early Eocene. The relative proportions of NPTs increased in the early middle Eocene and was highest during NP 18 ( $20 \%$ of species). The late Eocene was characterized by disappearance of PTs, leaving only one presumed nonplanktotrophic species (V. arangia) in NP 20.

When the larval modes of Volutospina are incorporated in the phylogeny, planktotrophy appears to be the plesiomorphic state, given the substantially higher frequency of PTs across the clade (Krug et al. 2015; Collin and Moran 2018). Non-planktotrophy has independently arisen at least three times in this clade (Fig. 2, white circles), and there is no evidence that reversals of larval mode occurred (although the larval mode of $V$. arangia remains unknown, and therefore the possibility that one reversal took place cannot be definitively ruled out). Of the seven NPTs in this clade, four originated from a single mode change $(V$. dalli, $V$. arangia, $V$. haleana, and $V$. sayana). The other two originations $(V$. selseiensis and $V$. clayi) coincided with larval mode changes but did not give rise to any new species.

The pattern of observed lineage diversity shows an increasing preponderance of NPTs; however, this is clearly driven by a dramatic extinction of PTs between NP 17 and NP 1920 (Table 1, Fig. 3). This extinction took place simultaneously in Europe and North America, but eliminated all APB species, leaving the single surviving American species, Volutospina arangia.

Comparing speciation between PTs and NPTs produces no statistically significant difference (Mann-Whitney $U$-test, $p=0.47$ ), with
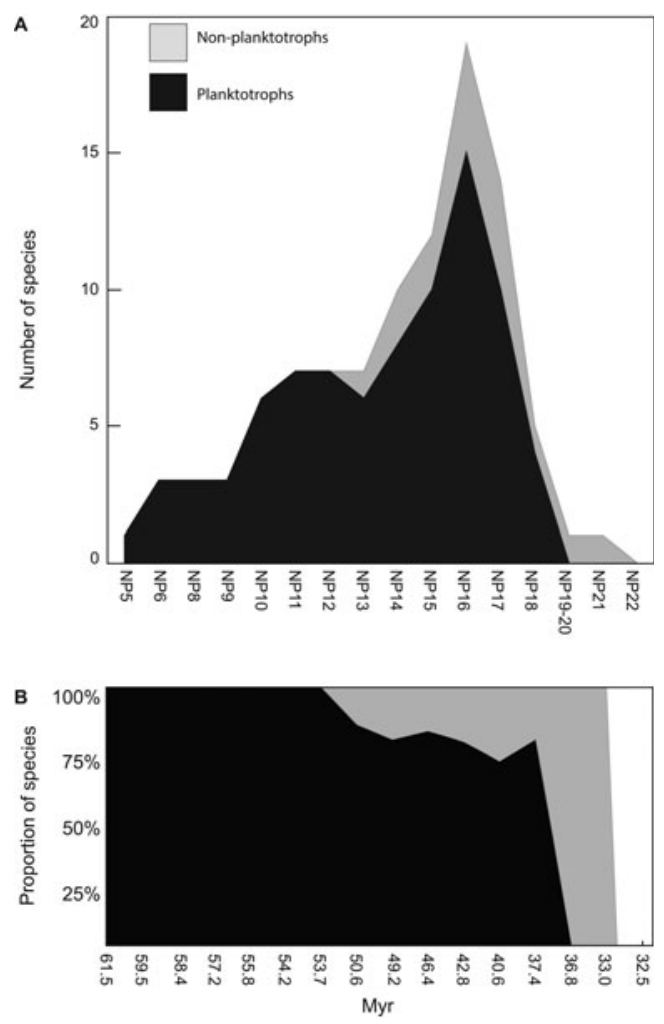

FIGURE 3. A, Number of planktotrophic and nonplanktotrophic Volutospina. B, Relative abundance of planktotrophic and non-planktotrophic Volutospina. See zones noted in Table 1.

a mean PT speciation rate of 0.252 per species, per million years, and mean NPT speciation rate 0.162 per species, per million years (Tables $3,5)$. Extinction rate also did not differ significantly (Mann-Whitney $U$-test, $p=0.41$ ), with a mean PT extinction rate of 0.09 per species, per million years and a mean NPT extinction rate of 0.16 per species, per million years (Tables 3, 5). PT net speciation rates had a mean of 0.164 from 12 time steps, while NPT net speciation rates had a mean of 0.01 from 8 time steps (Table 6). These differences were not statistically significant, including when time steps of 0 change were removed from the analysis.

\section{Discussion}

Paleogeographic Range.-Hansen's (1980) study on fossil Volutidae (including Volutospina examined here) from the GCP supported 
TABLE 5. Speciation and extinction rates (per species per million years) of planktotroph and non-planktotroph Volutospina.

\begin{tabular}{lcccc}
\hline \hline Timestep & $\begin{array}{c}\text { PT speciations per species } \\
\text { per million years }\end{array}$ & $\begin{array}{c}\text { NPT speciations per } \\
\text { species per million years }\end{array}$ & $\begin{array}{c}\text { PT extinctions per species } \\
\text { per million years }\end{array}$ & $\begin{array}{c}\text { NPT extinctions per } \\
\text { species per million years }\end{array}$ \\
\hline 1 & 1.053 & 0.714 & 0 & 0 \\
2 & 0.667 & 0.357 & 0.667 & 0.179 \\
3 & 0 & 0 & 0 & 0 \\
4 & 0.714 & 0.227 & 0 & 0.114 \\
5 & 0.104 & 0 & 0 & 0.234 \\
6 & 0 & 0 & 0 & 0 \\
7 & 0.046 & 0 & 0.046 & 0 \\
8 & 0.204 & 0 & 0 & 0.714 \\
9 & 0.071 & & 0 & \\
10 & 0.162 & & 0 & \\
11 & 0 & & 0.152 & \\
12 & 0 & & 0.188 & \\
\hline
\end{tabular}

predictions that planktotrophic species would have larger geographic ranges than non-planktotrophic species (PTs had a median geographic range of 5.5 units, while NPTs spanned an average of 1.0 unit). Our results show a different pattern; two considerations may explain the discrepancy.

The first consideration is potential preservation bias within the fossil deposits of the two regions (GCP and $\mathrm{APB}$ ). The distribution of accessible fossiliferous outcrops in the APB may have underestimated the true extent of the geographic ranges. This, of course, is a ubiquitous problem in paleontology. The second consideration, which we view as a more relevant factor, is the relatively limited size of actual paleobiogeographic provinces in the APB during the late Paleocene and Eocene. Paleogeographic reconstructions of the Paleocene and Eocene vary with respect to the coastline of the United Kingdom and France, depending on the precise age of the sediments (King et al. 2016). The North Sea was connected to the Atlantic Ocean during the Paleogene by a northern passage between current-day Scotland and Norway. In this case, the shared waters covering the present United Kingdom and France were bordered on three sides by land (Zacke et al. 2009). There is some uncertainty as to when the southern passage (i.e., current-day English Channel) formed, so it is possible that there were two routes by which larvae could enter or exit the Hampshire and Paris Basins (Zacke et al. 2009). The precise timing of open- or closed-access routes is a topic of recent interest, but there is currently no consensus (King et al. 2016). In other words, the geographic ranges of Volutospina in the APB may have been smaller than those in North America because there was less habitable space in which mollusks could live. Results of a Mann-Whitney $U$-test of geographic range between GCP species and APB species (Table 3) is consistent with the hypothesis that the size of the biogeographic province may ultimately control the geographic range of all APB Volutospina. There is also some evidence to suggest that epeiric seas (such as the Hampshire and Paris Basins) may support a higher species-area relationship than open ocean-facing settings (such as the GCP) due to differences in physical conditions (Lagomarcino and Miller 2012).

Species of similar dispersive potential still differed in geographic-range size, suggesting larval mode is not a predictor of realized geographic range. However, an alternate relationship is revealed when short-lived and long-lived species (regardless of larval mode) are compared. Short-lived species occupy smaller geographic ranges than do the longer-enduring species (Mann-Whitney $U$-test, $p=0.04$ ). This result is similar to that of Hansen (1980), who found that widespread species have the longest durations, while species that are narrowly distributed exhibit the shortest durations.

Our conclusions on the macroevolutionary consequences of paleogeographic range size are limited, because this study only encompasses APB and GCP. While collectively a large area, it is relatively small relative to the world's Eocene sedimentary record. Limiting the study to two basins might obscure 
TABLE 6. Calculations of speciation and extinction rates. *Time-bin length based on Papazonni et al. (2017) until NP21. NP 21-23 based on Less and Ozcan (2012). PT, planktotroph; NPT, non-planktotroph; $\mathrm{NP}$, nanoplankton.

\begin{tabular}{|c|c|c|c|c|c|c|c|c|c|c|c|c|c|}
\hline $\begin{array}{l}\text { Time } \\
\text { step }\end{array}$ & $\begin{array}{l}\text { NP zone } \\
\text { at base of } \\
\text { boundary }\end{array}$ & $\begin{array}{l}\text { Length } \\
\text { of time } \\
\text { bin* }\end{array}$ & $\begin{array}{l}\text { Lower } \\
\text { boundary } \\
\text { age }\end{array}$ & $\begin{array}{l}\text { Length in } \\
\text { Myr since } \\
\text { last zone } \\
\text { boundary }\end{array}$ & $\begin{array}{l}\text { No. of } \\
\text { observed } \\
\text { lineages }\end{array}$ & $\begin{array}{c}\text { No. of } \\
\text { planktotrophic } \\
\text { lineages }\end{array}$ & $\begin{array}{l}\text { No. of PT } \\
\text { originations } \\
\text { from } \\
\text { planktotrophic } \\
\text { species }\end{array}$ & $\begin{array}{l}\text { No. of NPT } \\
\text { originations } \\
\text { from } \\
\text { planktotrophic } \\
\text { species }\end{array}$ & $\begin{array}{c}\text { Total } \\
\text { originations } \\
\text { from } \\
\text { planktotrophic } \\
\text { species }\end{array}$ & $\begin{array}{l}\text { PT per } \\
\text { species } \\
\text { speciation } \\
\text { rate } \\
\end{array}$ & $\begin{array}{l}\text { PT per } \\
\text { species } \\
\text { per Myr } \\
\text { speciation } \\
\text { rate } \\
\text { (length of } \\
\text { previous } \\
\text { time bin) }\end{array}$ & $\begin{array}{l}\text { No. of } \\
\text { non-planktotrophic } \\
\text { lineages }\end{array}$ & $\begin{array}{c}\text { No. of NPT } \\
\text { originations from } \\
\text { non-planktotrophic } \\
\text { species }\end{array}$ \\
\hline 1 & NP5 & $59.5-61.4$ & 61.4 & 1.9 & 1 & 1 & N/A & N/A & N/A & N/A & N/A & 0 & N/A \\
\hline 2 & NP6 & $59.0-59.5$ & 59.5 & 0.5 & 3 & 3 & 2 & 0 & 2 & 2.00 & 1.05 & 0 & N/A \\
\hline 3 & NP8 & $57.2-58.4$ & 58.4 & 1.8 & 3 & 3 & 1 & 0 & 1 & 0.33 & 0.67 & 0 & N/A \\
\hline 4 & NP9 & $55.8-57.2$ & 57.2 & 1.4 & 3 & 3 & 0 & 0 & 0 & 0 & 0 & 0 & N/A \\
\hline 5 & NP10 & $54.2-55.8$ & 55.8 & 1.6 & 6 & 6 & 3 & 0 & 3 & 1.00 & 0.71 & 0 & N/A \\
\hline 6 & NP11 & $53.7-54.2$ & 54.2 & 0.5 & 7 & 7 & 1 & 0 & 1 & 0.17 & 0.10 & 0 & N/A \\
\hline 7 & NP12 & $50.6-53.7$ & 53.7 & 3.1 & 7 & 7 & 0 & 0 & 0 & 0 & 0 & 0 & N/A \\
\hline 8 & NP13 & $49.2-50.6$ & 50.6 & 1.4 & 7 & 6 & 0 & 1 & 1 & 0.14 & 0.05 & 1 & N/A \\
\hline 9 & NP14 & $46.4-49.2$ & 49.2 & 2.8 & 10 & 8 & 2 & 0 & 2 & 0.29 & 0.20 & 2 & 1 \\
\hline 10 & NP15 & $42.8-46.4$ & 46.4 & 3.6 & 12 & 10 & 2 & 0 & 2 & 0.20 & 0.07 & 2 & 1 \\
\hline 11 & NP16 & $40.6-42.8$ & 42.8 & 2.2 & 19 & 15 & 5 & 2 & 7 & 0.58 & 0.16 & 4 & 0 \\
\hline 12 & NP17 & $37.4-40.6$ & 40.6 & 3.2 & 14 & 10 & 0 & 0 & 0 & 0 & 0 & 4 & 1 \\
\hline 13 & NP18 & $36.8-37.4$ & 37.4 & 0.6 & 5 & 4 & 0 & 0 & 0 & 0 & 0 & 1 & 0 \\
\hline 14 & NP19-20 & $34.4-36.8$ & 36.8 & 2.4 & 1 & 0 & 0 & 0 & 0 & 0 & 0 & 1 & 0 \\
\hline 15 & NP21 & $34.4-33.0$ & 33 & 1.4 & 1 & 0 & 0 & 0 & 0 & 0 & 0 & 1 & 0 \\
\hline 16 & NP22 & $33.0-32.5$ & 32.5 & 0.5 & 0 & 0 & 0 & 0 & N/A & N/A & N/A & 0 & 0 \\
\hline
\end{tabular}

TABLE 6. Continued.

\begin{tabular}{|c|c|c|c|c|c|c|c|c|c|c|c|c|c|}
\hline $\begin{array}{l}\text { Time } \\
\text { step }\end{array}$ & $\begin{array}{c}\text { No. of PT originations } \\
\text { from } \\
\text { non-planktotrophic } \\
\text { lineages }\end{array}$ & $\begin{array}{c}\text { Total } \\
\text { originations } \\
\text { from NPT }\end{array}$ & $\begin{array}{l}\text { NPT per } \\
\text { species } \\
\text { speciation } \\
\text { rate } \\
\end{array}$ & $\begin{array}{l}\text { NPT per } \\
\text { species per } \\
\text { Myr } \\
\text { speciation } \\
\text { rate } \\
\end{array}$ & $\begin{array}{c}\text { PT } \\
\text { extinctions }\end{array}$ & $\begin{array}{l}\text { PT per } \\
\text { species } \\
\text { extinction } \\
\text { rate } \\
\end{array}$ & $\begin{array}{l}\text { PT per } \\
\text { species per } \\
\text { Myr } \\
\text { extinction } \\
\text { rate }\end{array}$ & $\begin{array}{c}\text { NPT } \\
\text { extinctions }\end{array}$ & $\begin{array}{l}\text { NPT per } \\
\text { species } \\
\text { extinction } \\
\text { rate }\end{array}$ & $\begin{array}{l}\text { NPT per } \\
\text { species per } \\
\text { Myr } \\
\text { extinction } \\
\text { rate }\end{array}$ & $\begin{array}{c}\text { Proportion } \\
\text { NP }\end{array}$ & $\begin{array}{l}\text { PT net } \\
\text { speciation } \\
\text { rate }\end{array}$ & $\begin{array}{l}\text { NPT net } \\
\text { speciation } \\
\text { rate }\end{array}$ \\
\hline 1 & N/A & N/A & N/A & N/A & N/A & N/A & N/A & $\mathrm{N} / \mathrm{A}$ & N/A & $\mathrm{N} / \mathrm{A}$ & 0 & N/A & N/A \\
\hline 2 & N/A & N/A & N/A & N/A & 0 & 0 & 0 & N/A & N/A & N/A & 0 & 1.05 & N/A \\
\hline 3 & N/A & N/A & N/A & $\mathrm{N} / \mathrm{A}$ & 1 & 0.33 & 0.67 & N/A & N/A & $\mathrm{N} / \mathrm{A}$ & 0 & 0 & N/A \\
\hline 4 & $\mathrm{~N} / \mathrm{A}$ & N/A & N/A & N/A & 0 & 0 & 0 & N/A & N/A & N/A & 0 & 0 & N/A \\
\hline 5 & N/A & N/A & N/A & N/A & 0 & 0 & 0 & N/A & N/A & N/A & 0 & 0.71 & N/A \\
\hline 6 & N/A & N/A & N/A & N/A & 0 & 0 & 0 & N/A & N/A & N/A & 0 & 0.10 & N/A \\
\hline 7 & N/A & N/A & N/A & $\mathrm{N} / \mathrm{A}$ & 0 & 0 & 0 & N/A & N/A & N/A & 0 & 0 & N/A \\
\hline 8 & N/A & N/A & N/A & $\mathrm{N} / \mathrm{A}$ & 1 & 0.14 & 0.05 & N/A & N/A & N/A & 0.14 & 0 & $\mathrm{~N} / \mathrm{A}$ \\
\hline 9 & 0 & 1 & 1.00 & 0.71 & 0 & 0 & 0 & 0 & 0 & 0 & 0.20 & 0.20 & 0.71 \\
\hline 10 & 0 & 1 & 1.00 & 0.36 & 0 & 0 & 0 & 1 & 0.50 & 0.18 & 0.17 & 0.07 & 0.18 \\
\hline 11 & 0 & 0 & 0 & 0 & 0 & 0 & 0 & 0 & 0 & 0 & 0.21 & 0.16 & 0 \\
\hline 12 & 0 & 1 & 0.50 & 0.23 & 5 & 0.33 & 0.15 & 1 & 0.25 & 0.11 & 0.29 & -0.15 & 0.11 \\
\hline 13 & 0 & 0 & 0 & 0 & 6 & 0.60 & 0.19 & 3 & 0.75 & 0.23 & 0.20 & -0.19 & -0.23 \\
\hline 14 & 0 & 0 & 0 & 0 & N/A & $\mathrm{N} / \mathrm{A}$ & N/A & 0 & 0 & 0 & 1.00 & N/A & 0 \\
\hline 15 & 0 & 0 & 0 & 0 & N/A & N/A & N/A & 0 & 0 & 0 & 1.00 & N/A & 0 \\
\hline 16 & 0 & 0 & 0 & 0 & N/A & N/A & $\mathrm{N} / \mathrm{A}$ & 1 & 1.00 & 0.71 & 0 & N/A & -0.71 \\
\hline
\end{tabular}


larger-scale patterns, but a global study is beyond the scope of this study.

Changes in Larval Mode.-A few general geographic trends in larval modes are known from studies of extant marine invertebrates. Jablonski and Lutz (1980) noted that the proportion of NPTs relative to PTs increased with water depth. But living volutids (all that are known are NPTs) occur in both shallow and deeper waters. And because early Cenozoic deposits do not show trends toward deeper water environments, water depth is unlikely to be causing observed switches and trends (Hansen 1978). Additionally, continental positions (reconstructed with paleomagnetic data) indicate only minor changes in the paleolatitude of both the GCP and the ABP (Hansen 1978; Torsvik et al. 2012) during the early Cenozoic; therefore, changes in developmental mode cannot be attributed to changes in latitude.

A steady trend of global cooling took place throughout most of the time period studied herein, beginning after the early Eocene climatic optimum, resulting in the onset of ephemeral $(\sim 36 \mathrm{Ma})$ and then permanent ( 34 Ma) Antarctic ice sheets (Zachos et al. 2001). If a relationship between larval development and latitude is mediated by temperature, a period of cooling might explain larger numbers of NPTs (due to less stratification, and increased potential for upwelling). However, it is doubtful that global temperature changes caused the developmental mode changes in Volutospina, as most diversification of PTs took place during the Lutetian, the same time period when most non-planktotrophic lineages originated.

Macroevolutionary Effects of Larval Mode.-It is essential that we consider selection and sorting hierarchically if we are to understand macroevolutionary trends throughout life history (Gould 1998; Congreve et al. 2018). This in turn necessitates the integration of phylogenetic, ecological, and paleoenvironmental information into a coherent interpretation of evolution of a clade (Lamsdell et al. 2017). For almost 50 years, studies of gastropods in the fossil record have reported that NPTs had high rates of both speciation and extinction, and at least some neogastropod clades accumulated more rapidly over time (Shuto 1974; Hansen 1978, 1980, 1982; Jablonski 1982, 1986; Jablonski and Lutz 1983). The results presented here indicate that, despite the multiple shifts to non-planktotrophy, this developmental mode change did not trigger increased cladogenesis, and indeed may have lowered speciation rates. Only one species was associated with each of two shifts to nonplanktotrophy (33\% of origins), while one additional shift resulted in the NPT clade containing only four species. This pattern does not support the commonly cited hypothesis that NPTs diversify at a higher rates and weakly supports the competing hypothesis that nonplanktotrophy results in decreased speciation by limiting the potential for allopatry (with speciation rates of NPTs found to be lower, but not significantly so). Results from this study are more consistent with findings from recent phylogenetic studies, which have challenged non-phylogenetic interpretations of the fossil record, and reveal independent origins of nonplanktotrophy are more common than might be expected and rarely precede bursts of cladogenesis (Lieberman et al. 1993; Hart et al. 1997; Hart 2000; Jeffery et al. 2003; Meyer 2003; Collin 2004; Hart and Podolsky 2005; Krug 2011). The hypothesis that non-planktotrophy increases extinction rates is only weakly supported, and the difference was not found to be statistically significant.

Gastropod dispersal ability (inferred via larval mode) has been repeatedly cited as a textbook example of how emergent traits can affect speciation rates (Jablonski and Lutz 1983; Jablonski 1986; Bergstrom and Dugatkin 2012). While some authors have invoked species selection, several widely cited paleontological studies did not actually calculate the emergent fitness of the clade (the net outcome of differential speciation and extinction rates), which is the crucial measure of species selection (Hansen 1980; Jablonski and Lutz 1983; Jablonski 1986). For Paleogene Volutospina, results here show that planktotrophic lineages disappeared from the paleontological record in two ways: through extinction (16 instances) and through character change to nonplanktotrophy (3 instances). Similarly, NPTs arose in two ways: speciation (3 instances) 
and character change in a planktotrophic ancestor (3 instances). Statistical comparison of speciation and extinction rates suggests diversification rate was only slightly higher for non-planktotrophic volutids. As the one clade of NPTs to diversify also was inferred to have arisen after a trans-Atlantic dispersal event (from a planktotrophic ancestor), the transition to non-planktotrophy may be only associated with speciation in a region with unoccupied volutid niche space, while nonplanktotrophy may have supported persistence of the colonizing population. However, one example is insufficient to draw general conclusions.

\section{Conclusions}

The aim of this research was to examine larval mode change in Volutospina from the Paleocene-Eocene deposits of the GCP and APB. Larval modes were mapped onto a phylogeny to determine the plesiomorphic larval mode and to hypothesize causes of larval mode switches. Both phylogenetic and nonphylogenetic approaches were used to explore macroevolutionary trends attributable to different larval modes.

The results indicated that species with planktotrophic larvae are geologically longer lived than species with non-planktotrophic development. Yet there was not a clear-cut relationship between larval mode and geographic-range size. Biogeographic distribution is the result of many variables, including dispersal potential, presence or absence of geographic barriers, and environmental tolerance. In the case of this study, the two larval modes did not possess significantly different geographic-range sizes, but paleobiogeography of the APB is a factor that could potentially limit species ranges, including those of high dispersal capabilities (in contrast, on a global scale, Halder and Das [2019] attributed the limited geographic distribution of most species within Indovolutinae to non-planktotrophic larval mode). The disparity in geographic-range size among taxa with similar dispersal potential may also be associated with their environmental tolerances, although no specific environmental changes were found to account for our observations.
Species sorting (Vrba and Gould 1986) can occur when the net diversification rate of a lineage is character-state dependent and is termed "species selection" for emergent traits (Stanley 1975; Vrba and Gould 1986; Jablonski 2008; Congreve et al. 2018). Despite comparative studies of species selection currently capturing moderate interest, confident identification of traits linked to diversification rates is exceedingly rare (Rabosky and McCune 2010; Rabosky and Goldberg 2015). In the case of larval mode, the organism-level trait of larval mode may have nonlinear (emergent) impacts on species duration and speciation rate through the mediating species-level traits' interpopulation connectivity (presumed to dampen speciation rate) and geographic range (presumed to impact extinction risk). Despite the seemingly substantial and likely irreversible transformation required, shifts to nonplanktotrophy have occurred in most clades, providing paleontologists with copious potential study subjects with which to evaluate the evolutionary origins and the resulting effects of reduced dispersal. Across the Volutospina clade, non-planktotrophy appears to have both dampened speciation and increased extinction risk and should presumably have been disfavored by species selection, ceteris paribus. However, while three independent planktotrophic lineages produced nonplanktotrophic lineages, no reversals were observed. This directionality may have led to a pattern resembling Figure 1C. However, examining the stratigraphic and geographic pattern of the extinction makes it clear that this natural experiment did not continue to an independent conclusion, but rather was truncated by a severe extinction event associated with global cooling and European shallow shelf area loss. When studied in proper phylogenetic and geographic context, Hansen's (1978) conclusions that non-planktotrophy (in species of Volutidae) was favored by species selection appear incorrect on two counts: (1) non-planktotrophy is not selectively favored, and (2) NPTs only "dominate" the clade after a major extinction leaves a single surviving species. This suggests that in the instance of Paleogene Volutospina, species selection does not appear to have driven the trend toward non- 
planktotrophy, but rather the clade follows the pattern proposed in Jablonski (2017), in which a chance shift in composition of the clade alters evolutionary dynamics.

The dominance of NPTs in extant Volutidae may similarly have been the result of contingency, either in extinction or through stochastic accumulation of irreversible transitions (therefore the result of biased origination of, rather than differences in, net speciation rates between NPTs and PTs) and is a suitable area for future research in phylogenetic context. While the differences in net diversification rates between nonplanktotrophic and planktotrophic Volutospina species were not found to be statistically significant in the present analysis, it is nevertheless possible that increased sample sizes may detect statistically distinguishable speciation and extinction rates or volatility. If increased sampling does suggest a statistically significant difference, then non-planktotrophic lineages, having potentially originated due to organism-level selection, are at greater risk of clade extinction due to macroevolutionary dynamics (Wagner et al. 2018); that is, living dead clades walking (Jablonski 2002; Sang et al. 2019). Only by examining the fossil and extant members of living clades in phylogenetic context can we properly answer these and other questions of evolutionary ecology (Lamsdell et al. 2017).

\section{Acknowledgments}

The authors extend their gratitude to G. Dietl and W. Bemis for their guidance and L. Skibinski and J. Todd for assistance in using collections. We also would like to thank J. C. Lamsdell and S. Tybout for discussions of volatility. Our appreciation also goes to our reviewers, who greatly helped us improve the article and suggested additional appropriate statistical methods.

\section{Literature Cited}

Allmon, W. D., and R. E. Martin. 2014. Seafood through time revisited: the Phanerozoic increase in marine trophic resources and its macroevolutionary consequences. Paleobiology 40:256-287.

Arnold, A. J., and K. Fristrup. 1982. The theory of evolution by natural selection: a hierarchical expansion. Paleobiology 8:113-129.

Bergstrom, C. T., and L. A. Dugatkin. 2012. Evolution. Norton, New York.
Boucot, A. 1975. Standing diversity of fossil groups in successive intervals of geologic time viewed in the light of changing levels of provincialism. Journal of Paleontology 49:1105-1111.

Collin, R. 2004. Phylogenetic effects, the loss of complex characters, and the evolution of development in calyptraeid gastropods. Evolution 58:1488-1502.

Collin, R., and M. P. Miglietta. 2008. Reversing opinions on Dollo's law. Trends in Ecology and Evolution 23:602-609.

Collin, R., O. R. Chaparro, F. Winkler, and D. Veliz. 2007. Molecular phylogenetic and embryological evidence that feeding larvae have been reacquired in a marine gastropod. Biological Bulletin 212:83-92.

Collin, R., and A. Moran. 2018. Evolutionary transitions in mode of development. Pp. 50-66 in T. J. Carrier, A. M. Reitzel, and A. Heyland, eds. Evolutionary ecology of marine invertebrate larvae. Oxford University Press, Oxford.

Congreve, C. R., A. R. Falk, and J. C. Lamsdell. 2018. Biological hierarchies and the nature of extinction. Biological Reviews 93:811-826.

Coyne, J. A., and H. A. Orr. 2004. Speciation. Sinauer, Sunderland, Mass.

Crampton, J. S., R. A. Cooper, A. G. Beu, M. Foote, and B. A. Marshall. 2010. Biotic influences on species duration: interactions between traits in marine molluscs. Paleobiology 36:204-223.

Darragh, T. A., and W. F. Ponder, eds. 1998. Family Volutidae. CSIRO Melbourne, Australia.

Duda, T. F., and S. R. Palumbi. 1999. Developmental shifts and species selection in gastropods. Proceedings of the National Academy of Sciences USA 96:10272-10277.

Fedosov, A. E., and N. Puillandre. 2012. Phylogeny and taxonomy of the Kermia-Pseudodaphnella (Mollusca: Gastropoda: Raphitomidae) genus complex: a remarkable radiation via diversification of larval development. Systematics and Biodiversity 10:447-477.

Foote, M., Crampton, J. S., Beu, A. G., and R. A. Cooper. 2008. On the bidirectional relationship between geographic range and taxonomic duration. Paleobiology 34:421-433.

Friend, D. S. 2021. Systematics of Paleocene-Eocene Volutospina (Neogastropoda) from the U.S. Gulf Coastal Plain and the AngloParisian Basin. PeerJ (in press).

Gilinsky, N. L. 1994. Volatility and the Phanerozoic decline of background extinction intensity. Paleobiology 20:445-458.

Goldberg, E. E., J. R. Kohn, R. Lande, K. A. Robertson, S. A. Smith, and B. Igić. 2010. Species selection maintains self-incompatibility. Science 330:493-495.

Gould, S. J. 1998. Gulliver's further travels: the necessity and difficulty of a hierarchical theory of selection. Philosophical Transactions of the Royal Society of London B 353:307-314.

Halder, K., and S. Das. 2019. New subfamily Indovolutinae and other volutids (Volutidae, Gastropoda) from the Eocene of Kutch, western India and their paleobiogeographic implications. Journal of Paleontology 93:899-915.

Hammer, Ø., D. A. T. Harper, and P. D. Ryan. 2001. PAST: Paleontological Statistics Software Package for Education and Data Analysis. Palaeontologia Electronica 4:9.

Hansen, T. A. 1978. Larval dispersal and species longevity in Lower Tertiary gastropods. Science 199:885-887.

Hansen, T. A. 1980. Influence of larval dispersal and geographic distribution on species longevity in neogastropods. Paleobiology 6:193-207.

Hansen, T. A. 1982. Modes of larval development in early Tertiary neogastropods. Paleobiology 8:367-377.

Hansen, T.A. 1997. Stabilizing selection and the comparative analysis of adaptation. Evolution 51:1341-1351.

Hart, M. 2000. Phylogenetic analyses of mode of larval development. Seminars in Cell and Developmental Biology 11:411-418.

Hart, M. W., and R. D. Podolsky. 2005. Mitochondrial DNA phylogeny and rates of larval evolution in Macrophiothrix brittlestars. Molecular Phylogenetics and Evolution 34:438-447. 
Hart, M. W., M. Byrne, and M. J. Smith. 1997. Molecular phylogenetic analysis of life-history evolution in asterinid starfish. Evolution 51:1848-1861.

Jablonski, D. 1982. Evolutionary rates and modes in late Cretaceous gastropods: role of larval ecology. Third North American Paleontological Convention Proceedings 1:257-262.

Jablonski, D. 1986. Larval ecology and macroevolution in marine invertebrates. Bulletin of Marine Science 39:565-587.

Jablonski, D. 1987. Heritability at the species level: analysis of geographic ranges of Cretaceous mollusks. Science 238:360-363.

Jablonski, D. 2000. Micro-and macroevolution: scale and hierarchy in evolutionary biology and paleobiology. Paleobiology 26:15-52.

Jablonski, D. 2002. Survival without recovery after mass extinctions. Proceedings of the National Academy of Sciences USA 99:81398144.

Jablonski, D. 2008. Species selection: theory and data. Annual Review of Ecology, Evolution, and Systematics 39:501-524.

Jablonski, D. 2017. Approaches to macroevolution: 2. Sorting of variation, some overarching issues, and general conclusions. Evolutionary Biology 44:451-475.

Jablonski, D., and R. A. Lutz. 1980. Molluscan larval shell morphology: ecological applications and paleontological applications. Pp. 323-379 in D. C. Rhoads and R. A. Lutz, eds. Skeletal growth of marine aquatic organisms. Plenum, New York.

Jablonski, D., and R. A. Lutz. 1983. Larval ecology of marine benthic invertebrates: paleobiological implications. Biological Reviews 58:21-89.

Jablonski, D., and J. W. Valentine. 1990. From regional to total geographic ranges: testing the relationship in Recent bivalves. Paleobiology 16:126-142.

Jackson, J. B. C. 1974. Biogeographic consequences of eurytopy and stenotopy among marine bivalves and their evolutionary significance. American Naturalist 108:541-560.

Jeffery, C. H., R. B. Emlet, and D. Littlewood. 2003. Phylogeny and evolution of developmental mode in temnopleurid echinoids. Molecular Phylogenetics and Evolution 28:99-118.

King, C. N., A. S. Gale, and T. L. Barry. 2016. A revised correlation of Tertiary rocks in the British Isles and adjacent areas of NW Europe. Geological Society of London Special Reports 27.

Krug, P. J. 2011. Patterns of speciation in marine gastropods: a review of the phylogenetic evidence for localized radiations in the sea. American Malacological Bulletin 29:169-187.

Krug, P. J., J. E. Vendetti, R. A. Ellingson, C. D. Trowbridge, Y. M. Hirano, D. Y. Trathen, A. K. Rodriguez, C. Swennen, N. G. Wilson, and Á. A. Valdés. 2015. Species selection favors dispersive life histories in sea slugs, but higher per-offspring investment drives shifts to short-lived larvae. Systematic Biology 64:983-999.

Lagomarcino, A. J., and A. I. Miller. 2012. The relationship between genus richness and geographic area in Late Cretaceous marine biotas: epicontinental sea versus open-ocean-facing settings. PLoS ONE 7:e40472.

Lamsdell, J. C., C. R. Congreve, M. J. Hopkins, A. Z. Krug, and M. E. Patzkowsky. 2017. Phylogenetic paleoecology: tree-thinking and ecology in deep time. Trends in Ecology and Evolution 32:452-463.

Less, G., and E. Özcan. 2012. Bartonian-Priabonian larger benthic foraminiferal events in the Western Tethys. Austrian Journal of Earth Sciences 105:129-140.

Lester, S. E., B. I. Ruttenberg, S. D. Gaines, and B. P. Kinlan. 2007. The relationship between dispersal ability and geographic range size. Ecology Letters 10:745-758.

Levinton, J. S. 1974. Trophic group and evolution in bivalve molluscs. Palaeontology 17:579-585.

Lieberman, B. S., and E. S. Vrba. 1995. Hierarchy theory, selection, and sorting. BioScience 45:394-399.

Lieberman, B. S., W. D. Allmon, and N. Eldredge. 1993. Levels of selection and macroevolutionary patterns in the turritellid gastropods. Paleobiology 19:205-215.
Liow, L. H., T. B. Quental, and C. R. Marshall. 2010. Marshall. 2010. When can decreasing diversification rates be detected with molecular phylogenies and the fossil record? Systematic Biology 59:646-659.

Marshall, C. R. 2017. Five palaeobiological laws needed to understand the evolution of the living biota. Nature Ecology and Evolution 1:0165.

McKinney, M. L. 1997. Extinction vulnerability and selectivity: combining ecological and paleontological views. Annual Review of Ecology and Systematics 28:495-516.

Meyer, C. P. 2003. Molecular systematics of cowries (Gastropoda: Cypraeidae) and diversification patterns in the tropics. Biological Journal of the Linnean Society 79:401-459.

Okasha, S. 2006. Evolution and the levels of selection. Clarendon Press, Oxford, U.K.

Papazzoni, C. A., V. Ćosović, A. Briguglio, and K. Drobne. 2017. Towards a calibrated larger foraminifera biostratigraphic zonation: celebrating 18 years of the application of shallow benthic zones. Palaios 32:1-4.

Penchaszadeh, P. E., P. Miloslavich, M. Lasta, and P. M. S. Costa. 1999. Egg capsules in the genus Adelomelon (Caenogastropoda: Volutidae) from the Atlantic coast of South America. Nautilus 113:56-63. Quental, T. B., and C. R. Marshall. 2009. Extinction during evolutionary radiations: reconciling the fossil record with molecular phylogenies. Evolution 63:3158-3167.

Rabosky, D. L. 2010. Extinction rates should not be estimated from molecular phylogenies. Evolution 64:1816-1824.

Rabosky, D. L., and E. E. Goldberg. 2015. Model inadequacy and mistaken inferences of trait-dependent speciation. Systematic Biology 64:340-355.

Rabosky, D. L., and A. R. McCune. 2010. Reinventing species selection with molecular phylogenies. Trends in Ecology and Evolution 25:68-74.

Reid, D. 1989. The comparative morphology, phylogeny and evolution of the gastropod family Littorinidae. Philosophical Transactions of the Royal Society of London B 324:1-110.

Robertson, R. 1974. Marine prosobranch gastropods: larval studies and systematics. Thalassia Jugoslavica 10:213-236.

Sang, S., D. S. Friend, W. D. Allmon, and B. M. Anderson. 2019. Protoconch enlargement in western Atlantic turritelline gastropod species following the closure of the Central American Seaway. Ecology and Evolution 9:5309-5323.

Scheltema, R. 1978. On the relationship between dispersal of pelagic veliger larvae and the evolution of marine prosobranch gastropods. Pp. 303-322 in J. Beardmore and B. Battaglia, eds. Marine organisms: genetics, ecology and evolution. Plenum, New York.

Scheltema, R. 1979. Mode of reproduction and inferred dispersal of prosobranch gastropods in the geologic past: consequences for biogeography and species evolution. Annual Meeting of the Geological Society of America Abstracts 11:126.

Scheltema, R. S. 1977. Dispersal of marine invertebrate organisms: paleogeographic and biostratigraphic implications. Pp. 73-108 in E. G. Kauffman and J. E. Hazel, eds. Concepts and methods in biostratigraphy. Dowden, Hutchinson, and Ross, Stroudsburg, Penn. Shuto, T. 1974. Larval ecology of prosobranch gastropods and its bearing on biogeography and paleontology. Lethaia 7:239-256.

Stanley, S. M. 1975. A theory of evolution above the species level. Proceedings of the National Academy of Sciences USA 72:646-650.

Stanley, S. M. 1979. Macroevolution, pattern and process. Freeman, San Francisco.

Stanley, S. M. 1986. Population size, extinction, and speciation: the fission effect in Neogene Bivalvia. Paleobiology 12:89-110.

Strathmann, R. 1974. The spread of sibling larvae of sedentary marine invertebrates. American Naturalist 108:29-44.

Strathmann, R. R. 1978. The evolution and loss of feeding larval stages of marine invertebrates. Evolution 32:894-906.

Thorson, G. 1950. Reproductive and larval ecology of marine bottom invertebrates. Biological Reviews 25:1-45. 
Torsvik, T. H., R. Van der Voo, U. Preeden, C. Mac Niocaill, B. Steinberger, P. V. Doubrovine, D. J. Van Hinsbergen, M. Domeier, C. Gaina, and E. Tohver. 2012. Phanerozoic polar wander, palaeogeography and dynamics. Earth-Science Reviews 114:325-368.

Vendetti, J. E. 2007. Protoconch comparative morphology in extinct and extant buccinid gastropods and its utility in paleobiogeography, systematics, and inferring larval mode. Malacologist 48:1-5. Vrba, E. S., and S. J. Gould. 1986. The hierarchical expansion of sorting and selection: sorting and selection cannot be equated. Paleobiology 12:217-228.

Wagner, P., R. E. Plotnick, and S. K. Lyons. 2018. Evidence for traitbased dominance in occupancy among fossil taxa and the decoupling of macroecological and macroevolutionary success. American Naturalist 192:E120-E138.

Zachos, J., M. Pagani, L. Sloan, E. Thomas, and K. Billups. 2001. Trends, rhythms, and aberrations in global climate 65 Ma to present. Science 292:686-693.

Zacke, A., S. Voigt, M. M. Joachimski, A. S. Gale, D. J. Ward, and T. Tütken. 2009. Surface-water freshening and high-latitude river discharge in the Eocene North Sea. Journal of the Geological Society of London 166:969-980.

Zelnik, Y. R., S. Solomon, and G. Yaari. 2015. Species survival emerge from rare events of individual migration. Scientific Reports 5:7877. 